\title{
Sexual dimorphism of flathead mullet (Mugil cephalus) from Northern Mindanao rivers using geometric morphometric analysis
}

\author{
Rose-Ann Silos, Brent Joy Hernando, Juzavil Juario, Sheryl Patiño, \\ Princess Angelie Casas, Jazzie D'Zeim Arreza, Angelo Responte, \\ Sonnie A. Vedra*
}

\author{
Department of Biological Sciences, Mindanao State University - \\ Iligan Institute of Technology, Iligan City, Philippines \\ ${ }^{*}$ College of Science and Environment, \\ Mindanao State University at Naawan, Misamis Oriental, Philippines
}

E-mail address: vedrasonnie@gmail.com

\begin{abstract}
Keywords: Cagayan de Oro River, discriminant function analysis, geographic separation, Mandulog River, predation.
\end{abstract}

\begin{abstract}
Sexual dimorphism is biologically important for determining the morphological traits of marine species. Flathead mullet (Mugil cephalus) was examined based on the patterns of sexual dimorphism from the two rivers in Northern Mindanao. The samples were collected from Cagayan de Oro River and Mandulog River to investigate phenotypic divergence and sexual dimorphism in two different populations of wild-caught $M$. cephalus using geometric morphology based on landmark basis. A total of 17 landmarks were identified to describe the left and right body shapes of the specimen using the TpsRelw (version 1) to obtain the warp scores of each population. Results of the Relative Warp Analysis show no significant variation in the body shape within the sexes in the respective sampling sites. Results of the discriminant function analysis (DFA) show that in Cagayan de Oro River there is no significant variation in the body shape of mullets between sexes suggesting no sexual dimorphism in the flathead mullets in Cagayan de Oro River. In contrast, Discriminant Function Analysis show that there is significant variation in body shape between sexes in Mandulog River in Iligan City suggesting presence of sexual dimorphism in the area which can be due to the presence of abundant and highly diverse predator species in Mandulog River. Sexual dimorphosm can be used by fishes as an adaptive mechanism to maximize predator-escape performance and survival capacity. Furthermore, there is a significant shape variation between populations of mullets in Cagayan de Oro and Mandulog River which can be interpreted as due to geographic isolation which serves as physical barrier on the gene pool. In conclusion, many factors could account for variation in body shape of Mugil cephalus including predation and biogeographical barriers.
\end{abstract}

\section{INTRODUCTION}

In the animal kingdom, sexual dimorphism in overall size and appearance occurs (Hedrick \& Temeles, 1989) and thus gathered the interest of many researchers to study on the sexual differences in morphology (Badyaev \& Martin, 2000; Schulte-Hostedde et. al. 2002). Sexual dimorphism can evolve when selection on males and females differs. Different trait values can differentially affect mating success in the two sexes, hence sexual selection is one of the most important drivers of sexual dimorphism (Darwin, 1871).

Sexual dimorphism, as this concept can be explained by sexual selection, prognosticate that variations in the reproductive roles between sexes may influence a sort of selection. There would then be sexual differences in morphological attributes such as the shape of its body (Casselman and Schulte-Hostedde, 2004). Yet, especially in terms of shape, sexual dimorphism could also be a functional adjustment for different habits of the sexes (Spoljaric and Reimchen, 2008; Burns and Rodd, 2009). There are varieties of factors wherein sexual dimorphism can result, including both sexual and natural selection. Sexual differences in external structures can also be driven by different 
reproductive roles, niche divergence between the sexes, preference of one sex for particular traits of the other sex, and intra-sexual competition can drive sexual differences in external structures (Slatkin, 1984; Shine, 1989; Andersson, 1994; and Kitano et al., 2007). Sexual dimorphism is required to understand the ecology, behaviour, and life history of a species like in the threespine stickleback (Gasterosteus aculeatus), sharing general features of secondary sexual characters across different populations was found out and that sexual dimorphism in some morphological traits was indicated having a genetic basis (Kitano et al, 2007).

Mugil cephalus (grey mullet), belonging to family Mugilidae, is the most abundant and commonly caught of all species which is primarily detritivorous, ingesting large amounts of organic matter, sand or mud from the sediment of waterways. It inhabits estuarine intertidal, freshwater and coastal marine habitats worldwide from approximately $42 \mathrm{~N}-42 \mathrm{~S}$ latitude. It supports commercial and recreational fisheries owing to the high protein and vitamins contained in the muscle tissue, the value of roe from females, and are a stable food source in many countries (Whitfield et al., 2012).

The body shape of grey mullet (colored bluish gray or greenish above, becoming silver along its body sides) looks cylindrical in its anterior and somewhat looks compressed in its posterior end. Approximately, it could reach a length of up to 18 " and could weigh up to 3 pounds (Hill, 2004).

Basically, males and females differ in their reproductive roles. Variations in selective pressures experienced by the sexes can ultimately result in the evolution of sexual dimorphism of morphological traits (Anderrson, 1994). Hence, the study was conducted to gather data on the sexual dimorphism of Mugil cephalus from the two rivers in Northern Mindanao, Cagayan de Oro River and Mandulog River hence the study was conducted.

The present study investigates phenotypic divergence and sexual dimorphism in two populations of Mugil cephalus from Mandulog River and Cagayan de Oro River. Specifically, it aims to quantify and visualize the mean shape differences between sexes (sexual dimorphism), and between populations and species (morphological divergence) using a geometric morphology based on landmarks analyses.

\section{MATERIALS AND METHODS}

\section{Samples}

Two populations of Mugil cephalus with a total of 40 samples were examined. Adult male and female fishes from the rivers of Mandulog (N 08.25493, E 124.26.26077) and Cagayan de Oro (N 08.48874, E 124.64066) with 20 samples (10 males and 10 females) from each river were collected (Fig. 1). Fish samples were collected by a fisherman using conventional fish nets at the early hours of the day. Samples were then immediately paralyzed and immobilized with an ice in an ice box and brought to the MSU-Iligan Institute of Technology laboratory for photography. 


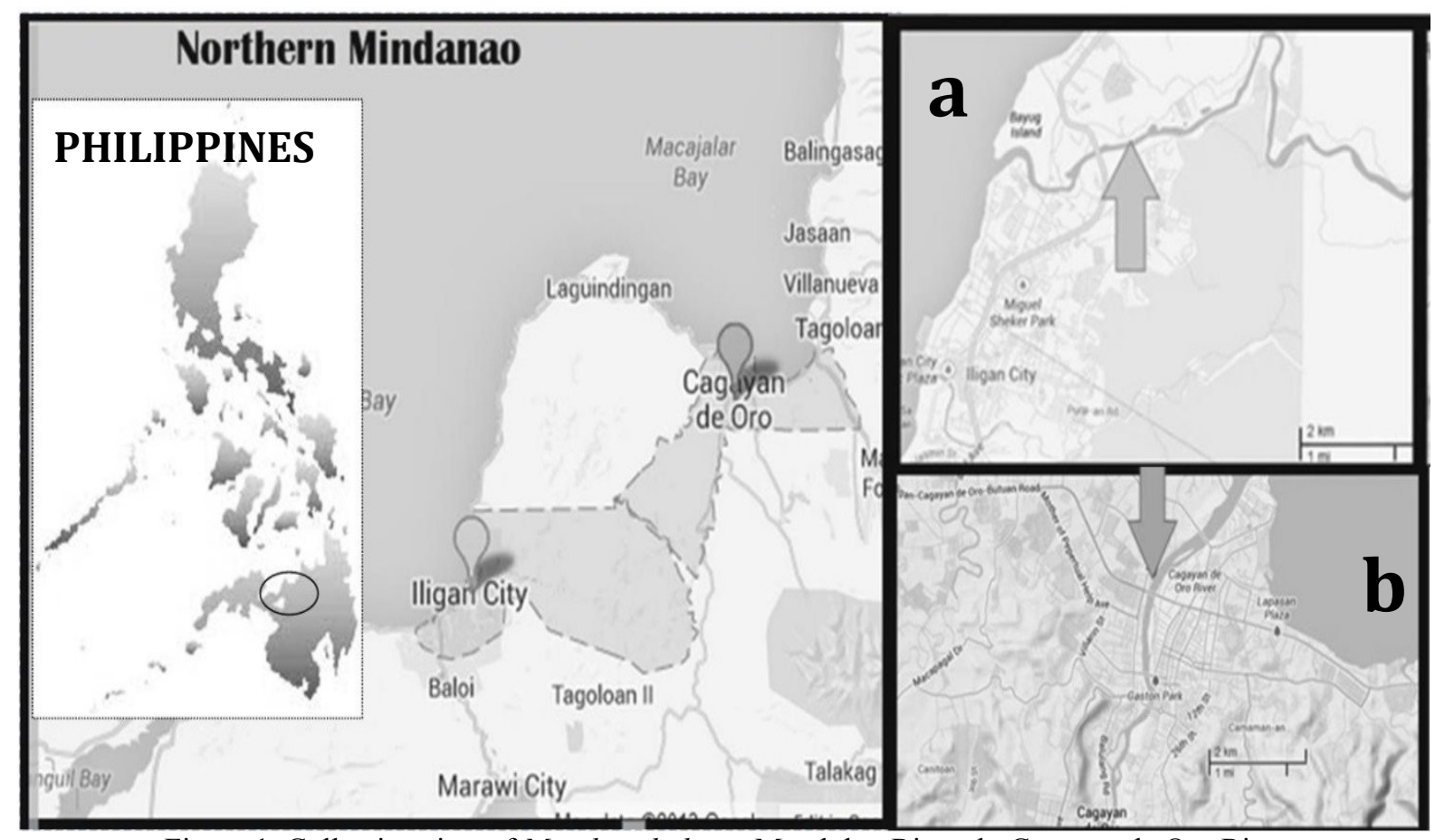

Figure 1. Collection sites of Mugil cephalus a. Mandulog River; b. Cagayan de Oro River.

\section{Morphometrics Analysis}

High definition photographs of the left side and right side of the samples were taken using a DSLR camera and a tripod angled at $90^{\circ}$. A total of 17 landmark points placed at homologous locations at the fish were chosen to quantify the overall shape (Fig 2).

Photographed images were then subjected to landmark-based geometric morphometric analysis. Each sample was landmarked thrice to minimize the errors in landmarking. Landmarks were digitized on the images using TpsDig (version 2).

\section{Analysis of Relative Warp Scores}

The TPS of the images of male and female Mugil cephalus were subjected to relative warp analysis using TpsRelw (version 1,45) along with a slider and link file dictating the type of each landmark used in the study.

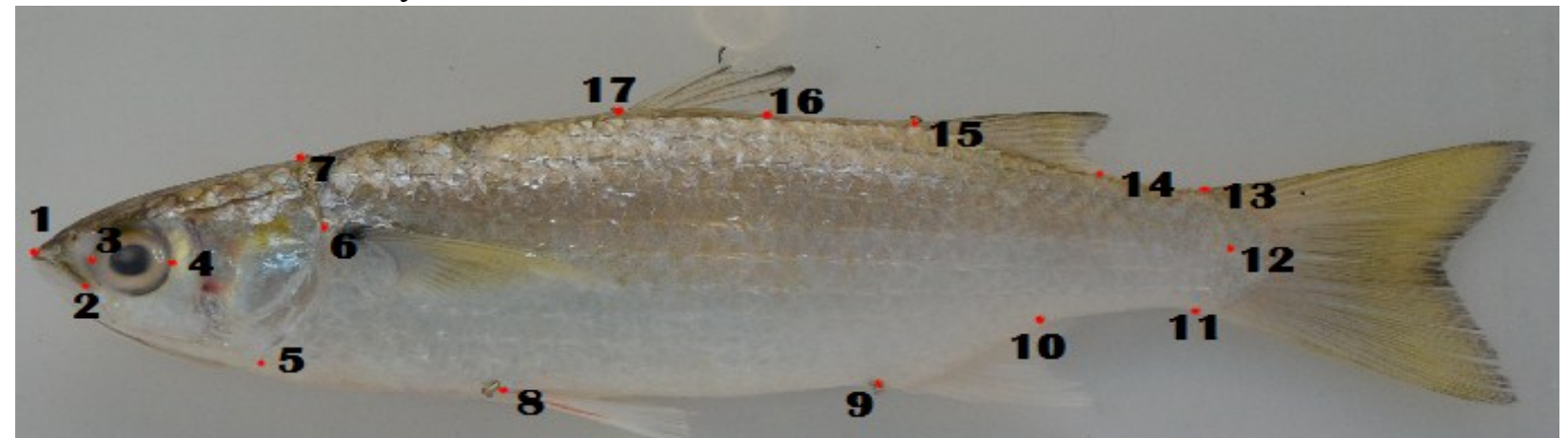

Figure 2. Landmarks for the geometric morphometric analysis of Mugil cephalus: (1) snout tip, (2) Axis of the jaws, (34) anterior and posterior orbit of the eye, (5) insertion of the operculum on lateral profile, (6) point of maximum extension of operculum on lateral profile, (7) midway between snout tip and dorsal fin; (8) anterior insertion of the caudal fin, (9-10) anterior and posterior insertion of the anal fin, $(11,13)$ dorsal and ventral region of the caudal peduncle, (12) posterior most body extremity, (14-15) anterior and posterior insertion of the 2nd dorsal fin, (16-17) anterior and posterior insertion of the 1 st dorsal fin. 
The landmarks were in two dimensional morpho-space grids where variations were shown as deformations of the grids. Images from each population were separated into male and female to produce consensus configuration of each sex to individually determine the shape variability of each population. Relative warps that contributed $5 \%$ and above to the overall data was used in the analysis using Paleontological Statistics developed by Hammer et al (2001). The results were depicted in histograms. To determine if shape varied significantly between sexes of Mugil cephalus, pooled partial warp scores of the sexes from both populations were subjected to Discriminant Function Analysis (DFA).

\section{RESULTS AND DISCUSSIONS}

\section{Body Shape Variation of Flathead Mullet}

The extent of the left body shape variation of normal female M. cephalus from Cagayan de Oro River is described by the five relative warps which explain $88.17 \%$ of the total variation. The pattern of shape change is summarized in Figure 3.
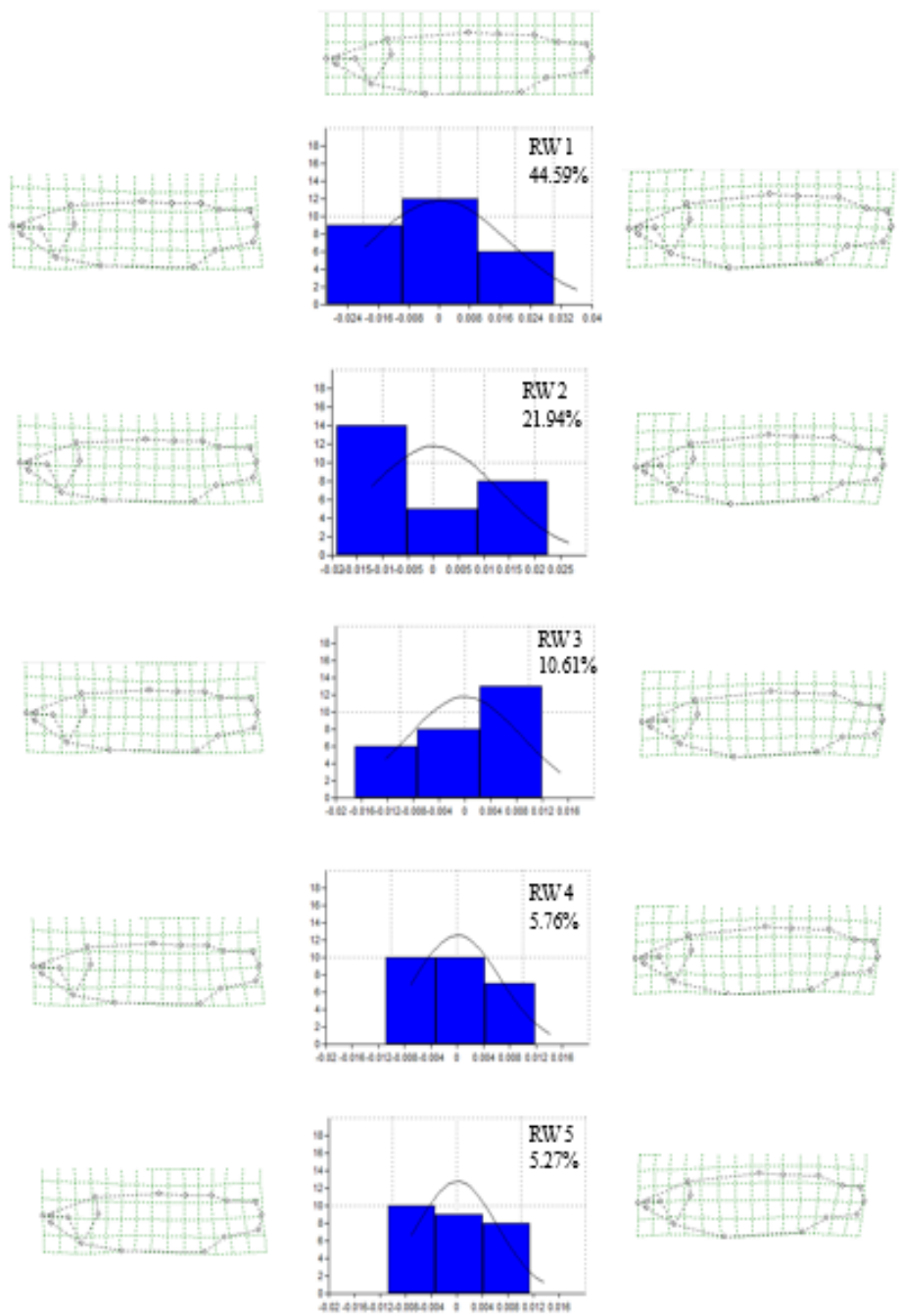

Figure 3. Summary of female left mullet body shape geometric morphometric analysis from Cagayan de Oro River. It shows the consensus morphology (uppermost figure) and the extremes of their variation in body shape produced by the first five relative warps explaining $88.17 \%$ of the total variation. $(\mathrm{RW} 1=44.59 \%, \mathrm{RW} 2=21.94 \%, \mathrm{RW} 3=10.61 \%$, $\mathrm{RW} 4=5.76 \%$, RW5 $=5.27 \%$ )

The variation in the left body shape of female mullets in Cagayan de Oro River ranges from $5.27 \%-44.59 \%$ which signifies that there is no significant variation in the left body shapes within the female population in the area. 
The extent of the left body shape variation of normal male $M$. cephalus from Cagayan de Oro River is described by the four relative warps which explain $86.44 \%$ of the total variation. The pattern of shape change is summarized in Figure 4.
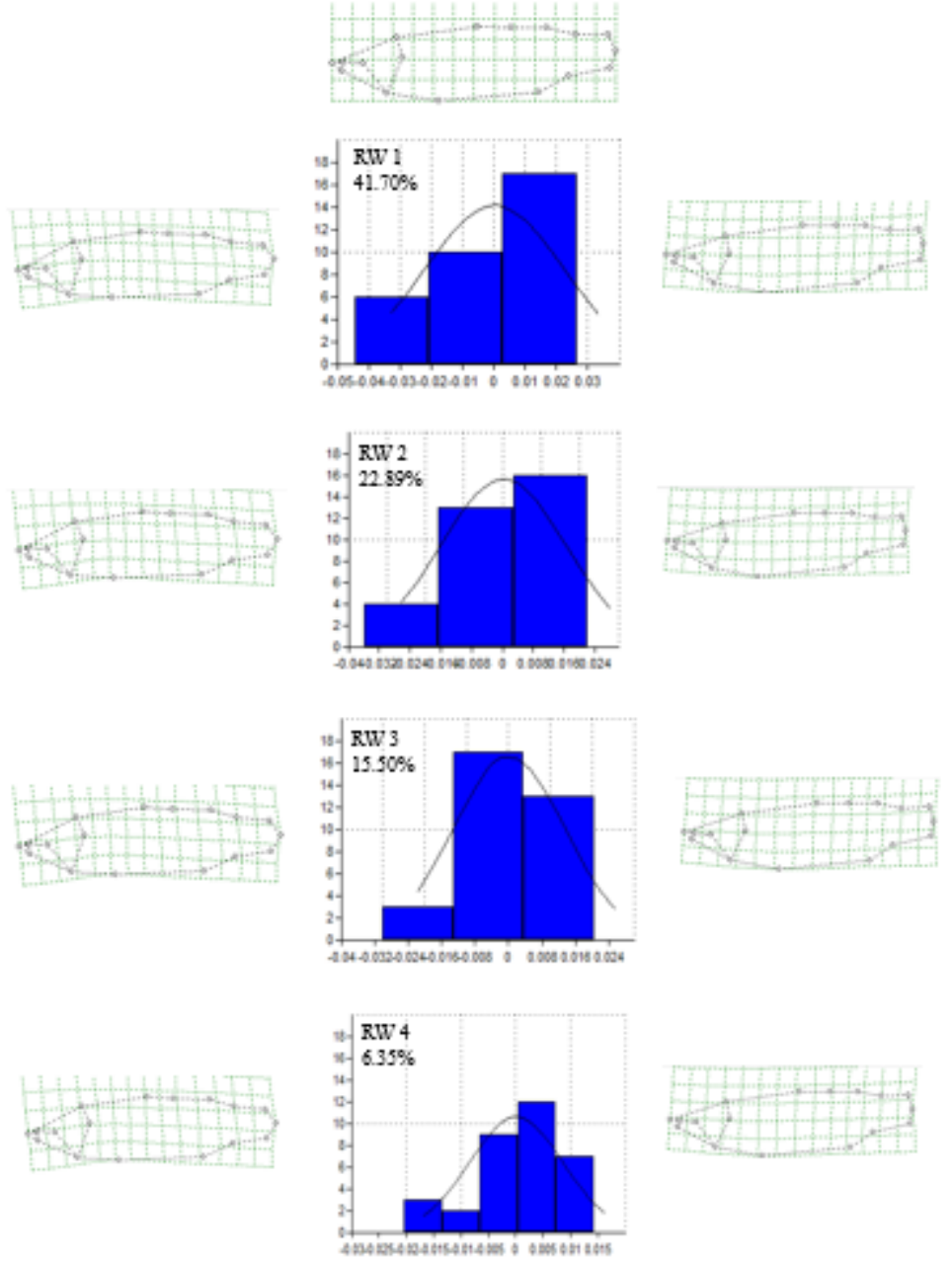

Figure 4. Summary of male left mullet body shape geometric morphometric analysis from Cagayan de Oro River. It shows the consensus morphology (uppermost figure) and the extremes of their variation in body shape produced by the first four relative warps explaining $86.44 \%$ of the total variation. (RW1 $=41.70 \%$, RW2 $=22.89 \%$, RW3 $=15.50 \%$, RW4 $=6.35 \%)$

The variation in left body size of male mullets in Cagayan de Oro River ranges from $6.35 \%$ - 41.70\%. The left body size of male mullets in Cagayan de Oro River varies insignificantly.

The extent of the right body shape variation of normal female M. cephalus from Cagayan de Oro River is described by the five relative warps which explain $89.37 \%$ of the total variation. The pattern of shape change is summarized in Figure 5. 

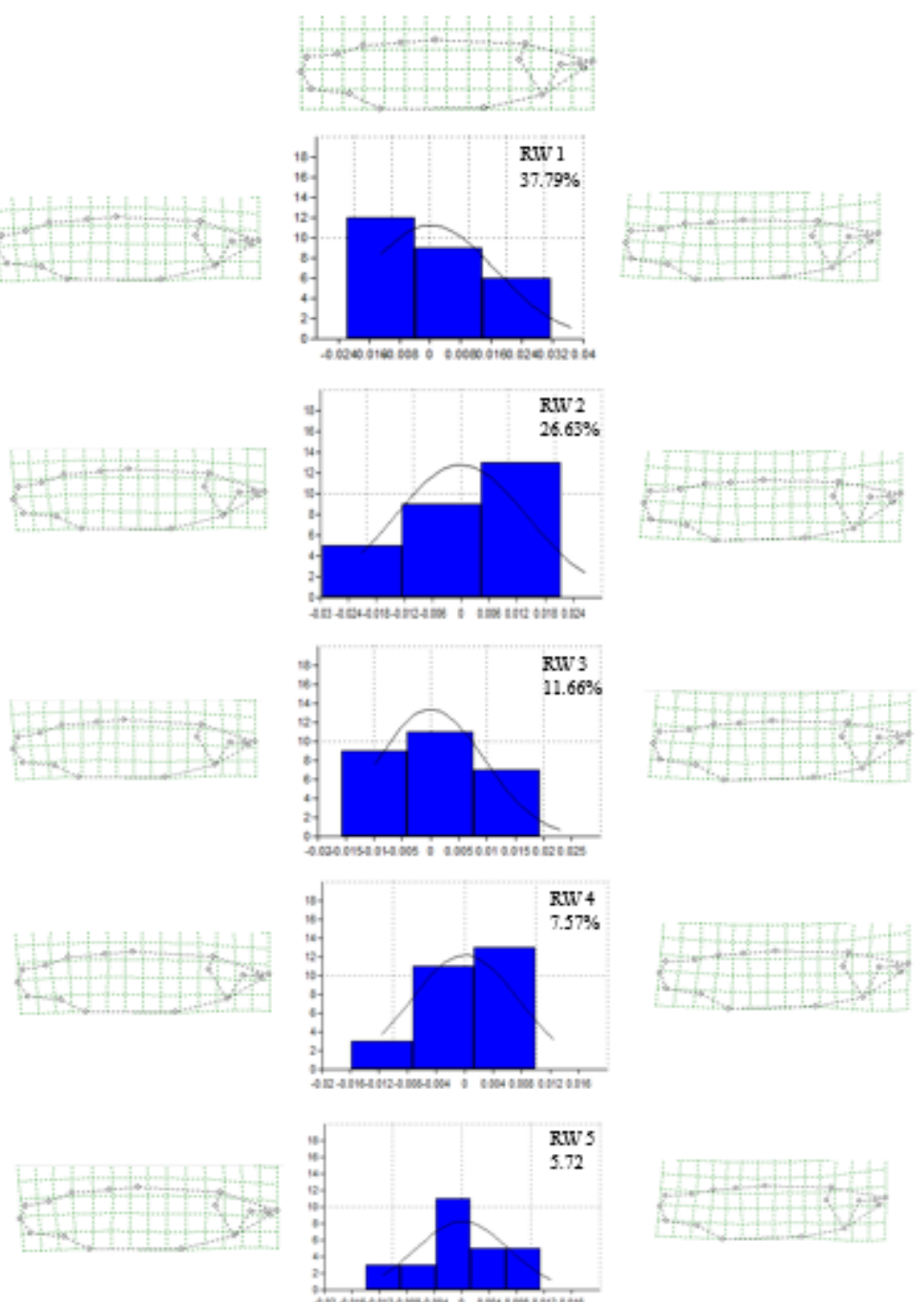

Figure 5. Summary of female right mullet body shape geometric morphometric analysis from Cagayan de Oro River. It shows the consensus morphology (uppermost figure) and the extremes of their variation in body shape produced by the first five relative warps explaining $89.37 \%$ of the total variation. $(\mathrm{RW} 1=37.79 \%$, RW2 $=26.63 \%$, RW3 $=11.66 \%$, RW4 $=7.57 \%$, RW5 $=5.72 \%$ )

The variation in the right body shape of female mullets in Cagayan de Oro River ranges from $5.27 \%-37.79 \%$. This means that the there is no significant variation in the right body shapes within the female population.

The extent of the right body shape variation of normal male M. cephalus from Cagayan de Oro River is described by the five relative warps which explain $90.19 \%$ of the total variation. The pattern of shape change is summarized in Figure 6. 


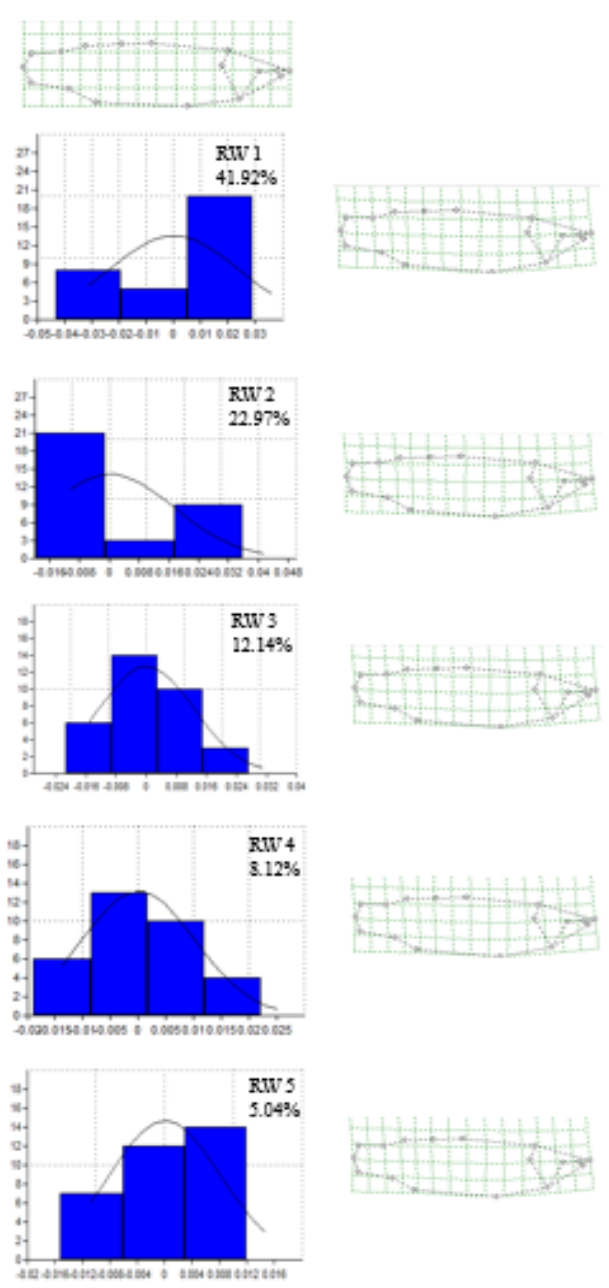

Figure 6. Summary of male right mullet body shape geometric morphometric analysis from Cagayan de Oro River. It shows the consensus morphology (uppermost figure) and the extremes of their variation in body shape produced by the first five relative warps explaining $90.19 \%$ of the total variation. $(\mathrm{RW} 1=41.92 \%$, RW2 $=22.97 \%, \mathrm{RW} 3=12.14 \%$, RW4 $=8.12 \%$, RW5 $=5.04 \%$ )

The variation in right body size of male mullets in Cagayan de Oro river ranges from $5.04 \%$ - 41.92\%. The right body size variation of male mullets in CDO River is insignificantly different.

The extent of the left body shape variation of normal female M. cephalus from Mandulog River is described by the five relative warps which explain $85.75 \%$ of the total variation. The pattern of shape change is summarized in Figure 7. 

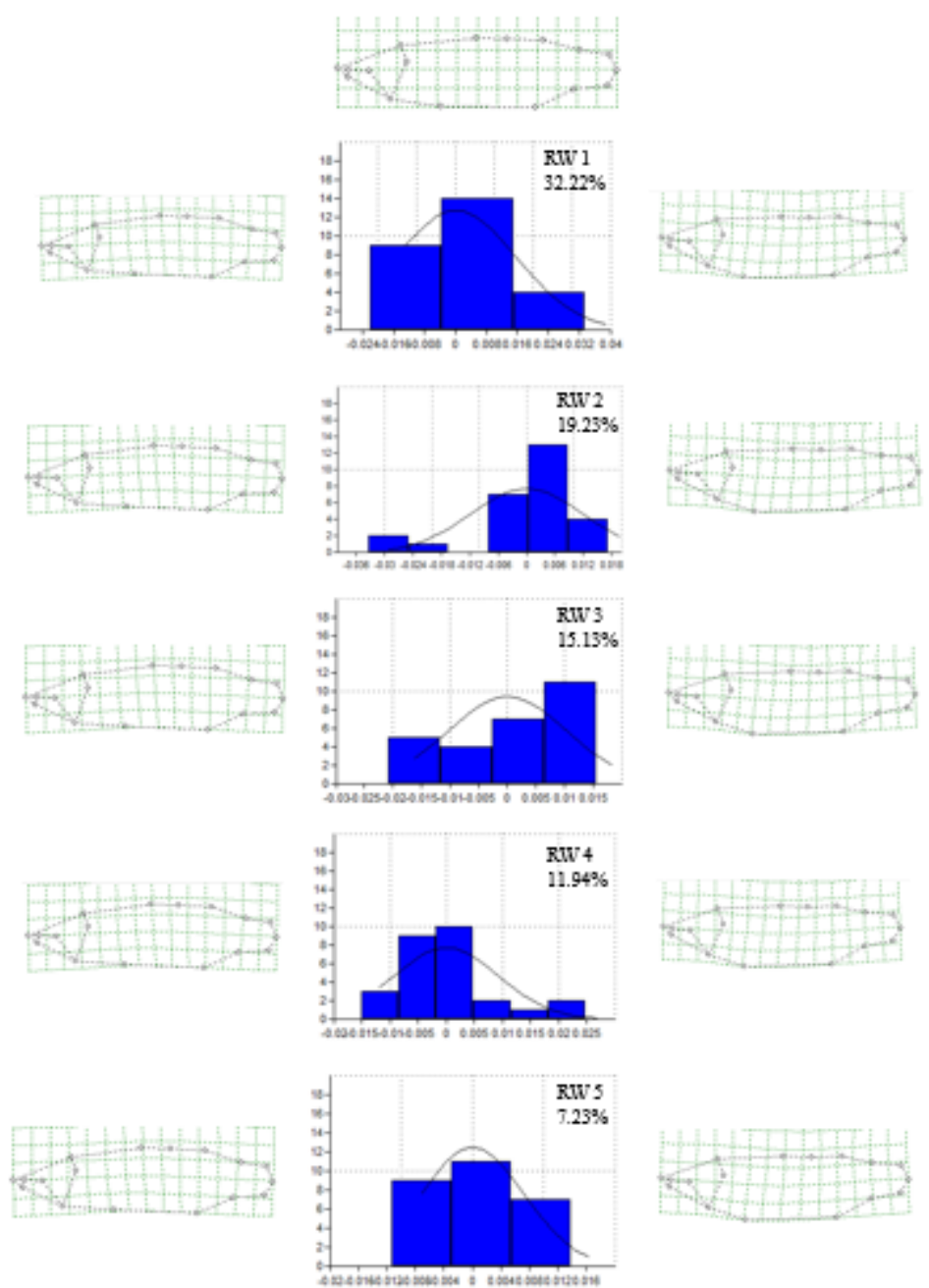

Figure 7. Summary of female left mullet body shape geometric morphometric analysis from Mandulog River. It shows the consensus morphology (uppermost figure) and the extremes of their variation in body shape produced by the first five relative warps explaining $85.75 \%$ of the total variation. $(\mathrm{RW} 1=32.22 \%$, RW2 $=19.23 \%$, RW3 $=15.13 \%$, RW4 $=$ $11.94 \%$, RW5 $=7.23 \%$ )

The variation in the left body shape of female mullets in Mandulog River ranges from $7.23 \%-32.22 \%$. There is no significant variation in the left body shapes within the female population in the area.

The extent of the left body shape variation of normal male M. cephalus from Mandulog River is described by the six relative warps which explain $85.21 \%$ of the total variation. The pattern of shape change is summarized in Figure 8. 

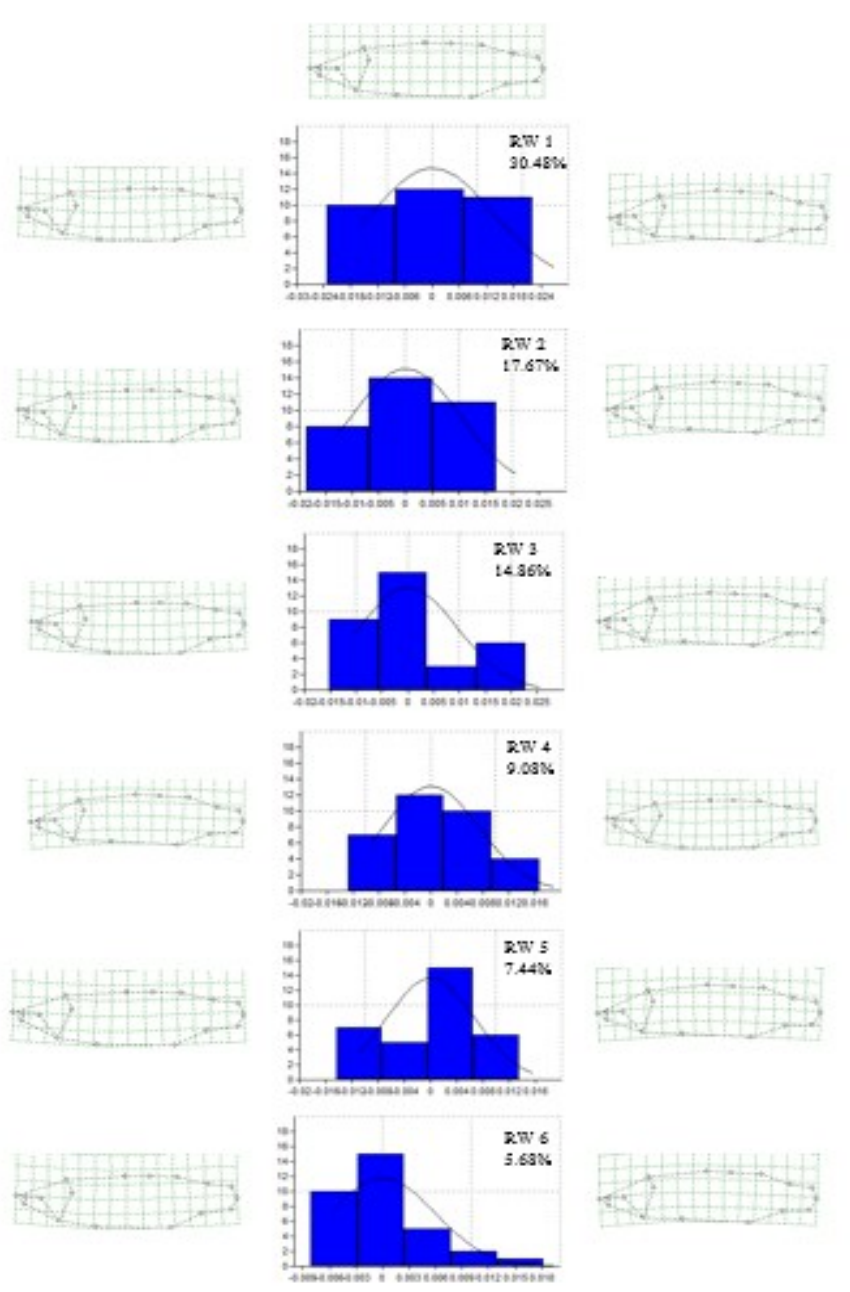

Figure 8. Summary of male left mullet body shape geometric morphometric analysis from Mandulog River. It shows the consensus morphology (uppermost figure) and the extremes of their variation in body shape produced by the first six relative warps explaining $85.21 \%$ of the total variation. $(\mathrm{RW} 1=30.48 \%$, RW2 $=17.67 \%$, RW3 $=14.86 \%$, RW4 $=$ $9.08 \%$, RW5 $=7.44 \%$, RW6 $=5.68 \%$ )

The variation in the left body shape of male mullets in Mandulog River ranges from $5.68 \%$ $30.48 \%$. This means that there is no significant variation in the left body shapes within the male population in the area.

The extent of the right body shape variation of normal female M. cephalus from Mandulog River is described by the four relative warps which explain $79.85 \%$ of the total variation. The pattern of shape change is summarized in Figure 9. 

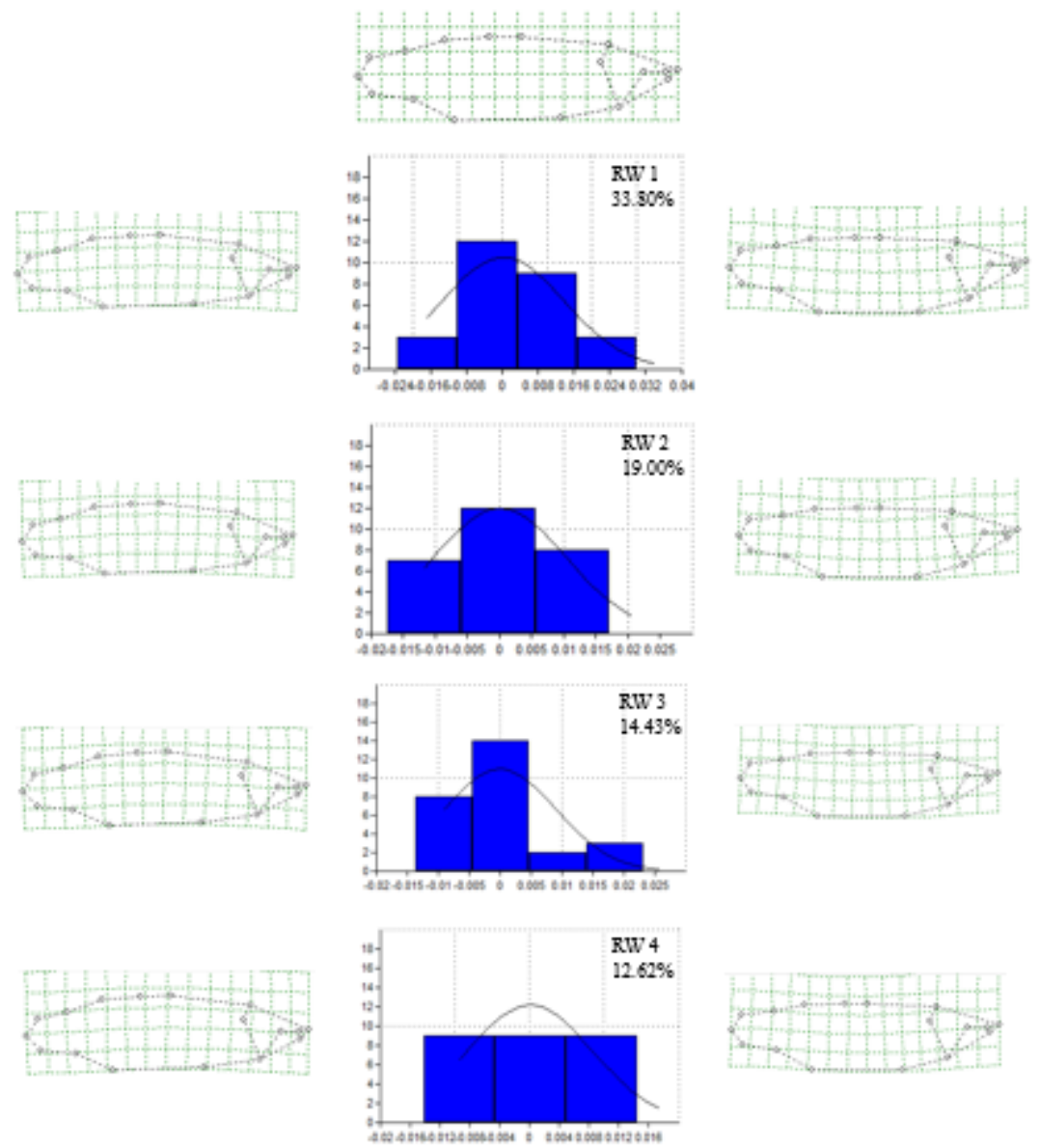

Figure 9. Summary of female right mullet body shape geometric morphometric analysis from Mandulog River. It shows the consensus morphology (uppermost figure) and the extremes of their variation in body shape produced by the first four relative warps explaining $79.85 \%$ of the total variation. $(\mathrm{RW} 1=33.80 \%$, RW2 $=19.00 \%$, RW3 $=14.43 \%$, RW4 $=$ 12.62)

The variation in the right body shape of female mullets in Mandulog River ranges from $12.62 \%-33.80 \%$ which signifies that there is no significant variation in the right body shapes within the female population in the area.

The extent of the right body shape variation of normal male M. cephalus from Mandulog River is described by the five relative warps which explain $81.99 \%$ of the total variation. The pattern of shape change is summarized in Figure 10. 


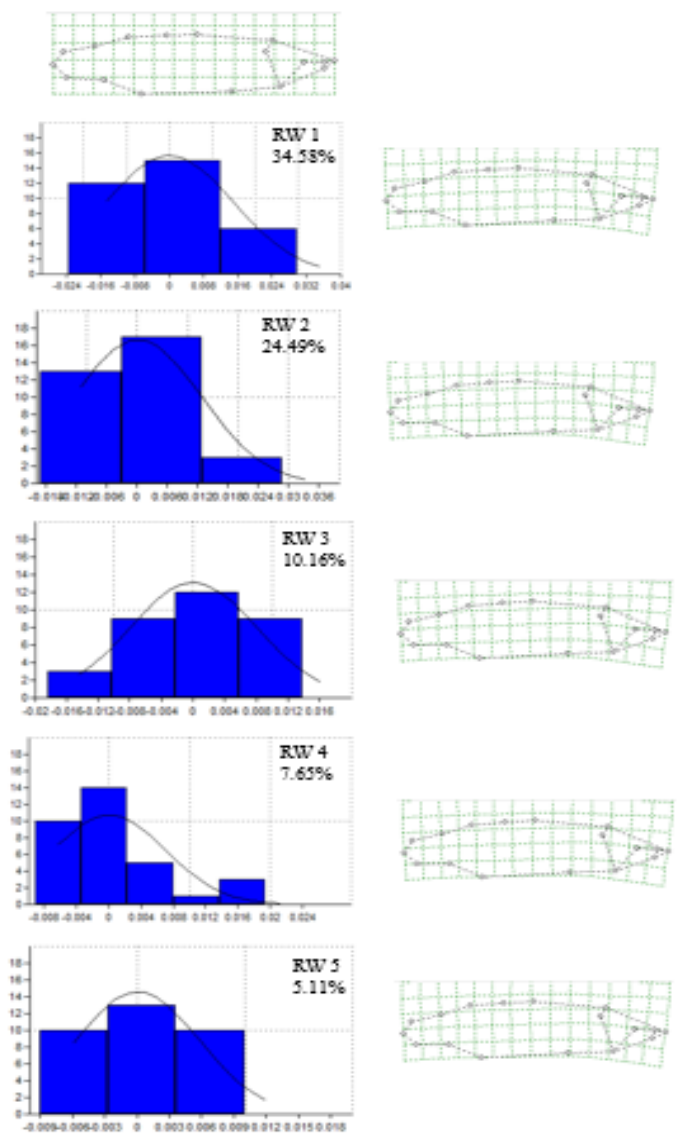

Figure 10. Summary of male right mullet body shape geometric morphometric analysis from Mandulog River. It shows the consensus morphology (uppermost figure) and the extremes of their variation in body shape produced by the first five relative warps explaining $81.99 \%$ of the total variation. $(\mathrm{RW} 1=34.58 \%$, RW2 $=24.49 \%$, RW3 $=10.16 \%$, RW4 $=$ 7.65 , RW5 $=5.11 \%$ )

The variation in the right body shape of male mullets in Mandulog River ranges from $5.11 \%$ - $34.58 \%$. There is no significant variation in the right body shapes within the male population in the area.

The overall result of the Relative Warp Analysis showed that there is no significant variation in body shape within the sexes of Mugil cephalus in Cagayan de Oro River and Mandulog River. This implies that within sex mullets have uniform body shape which can be due to natural and sexual selection of species. 


\section{Discriminant Function Analysis}

Using the relative warp data from landmark-based geometric morphometric analysis, the body shape variations between sexes within the same site was determined using Discriminant Function Analysis. Figure 11 shows that there is no significant variation in body shape between sexes of Mugil cephalus in Cagayan de Oro River suggesting absence of sexual dimorphism in the area.

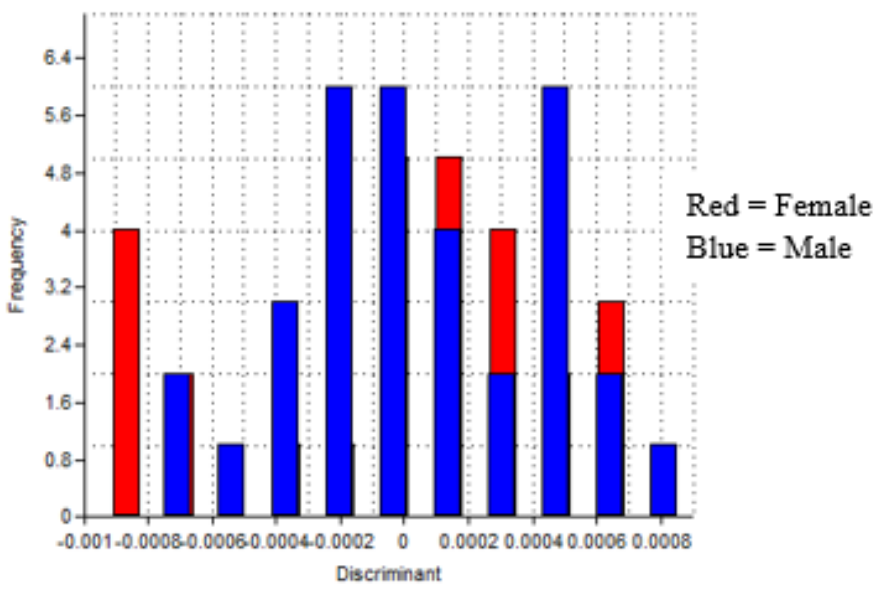

Figure 11. Graph of Discriminant Function Analysis of the relative warp scores of left body shapes among

The figure shows high degree of overlap in the frequency distribution of the relative warp scores of the male and female mullets in Cagayan de Oro River. This suggests that there is high degree of similarity in the body shape in both sides between the male and female mullets in Cagayan de Oro River.

Discriminant Functional Analysis result shown in Figure 12 suggests a significant variation in the frequency distribution of the relative warp scores between sexes in Mandulog River. Analysis show that higher than $50 \%$ of the pooled population of mullets in Mandulog River are correctly classified as male or female suggesting sexual dimorphism.

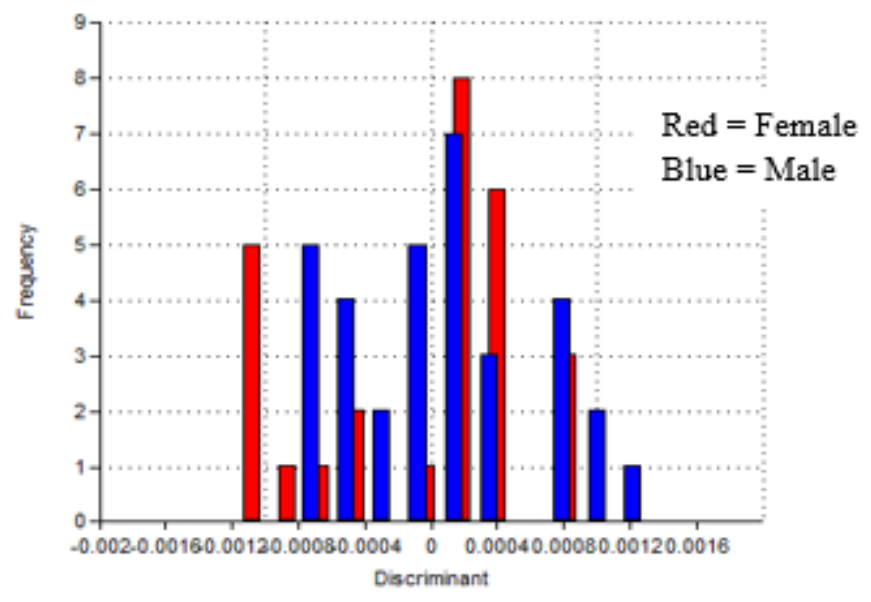

Figure 12. Graph of Discriminant Function Analysis of the relative warp scores of left body shapes among mullets from Mandulog River. 
The same result can also be applied to the right body shape of female and male mullets from Mandulog River as shown in Figure 13 which has greater than 50\% correctly classified value.

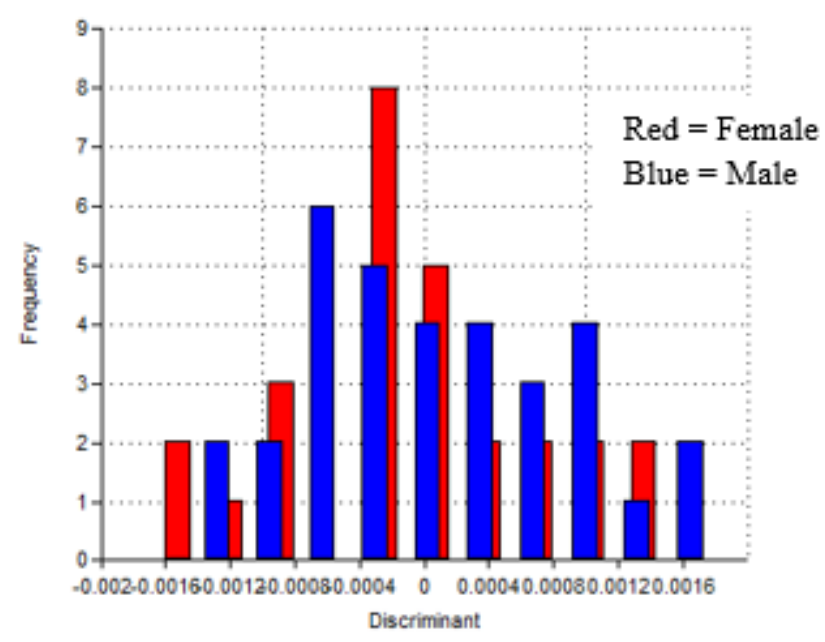

Figure 13. Graph of Discriminant Function Analysis of the relative warp scores of right body shapes among mullets from Mandulog River.

Variation in the body shape between the sexes is observed in Mandulog River. This means that there is an occurrence of sexual dimorphism of mullets in Mandulog River unlike in Cagayan River. According to Hendry et al., (2006) guppies (Peocillia reticulata) exhibit greater difference in body shape in high predation environments because males suffer higher predation than females thus favouring a body shape that maximizes predator-escape performance. This implies that there is relatively greater number of predators in Mandulog River than in Cagayan de Oro River. Altenatively sexual dimorphism may play an important role in schooling behavior as well as in sexual recognition of these species in environment characterized by turbid coastal waters secondary to high sediment load of riverine waters.

Discriminant function analysis was also applied to the body shape variations in both sexes between the sites using the relative warp data from landmark-based geometric morphometric analysis. As shown in Figure 14, the left body shape of female mullet from Cagayan de Oro River varied significantly from the left body shape of male from Mandulog River.

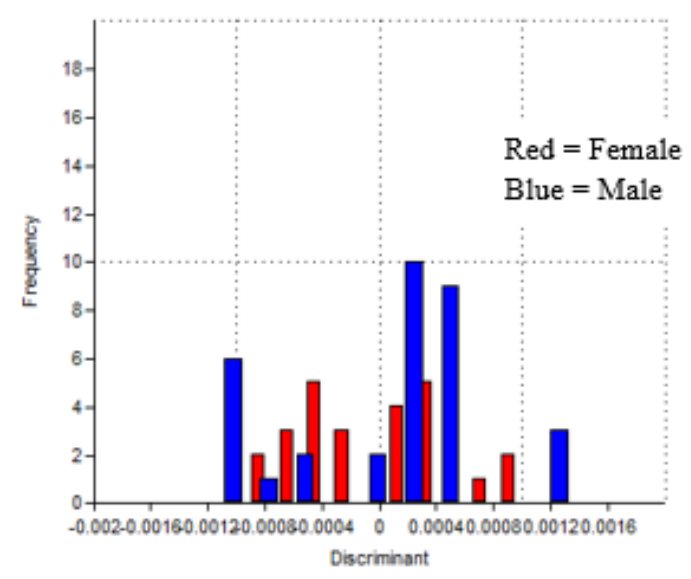

Figure 14. Graph of Discriminant Function Analysis of the relative warp scores of right body shape of female mullets from Cagayan de Oro River and right body shape of male mullets from Mandulog River. 
Figure 14 distinctly discriminates the males from the female mullets. The figure shows different group of body shape, thus left body shapes of female and male mullets in Cagayan de Oro River and Mandulog River respectively, are statistically different. The result can also be applied to the right body shapes of female and male mullets from Cagayan de Oro River and Mandulog River respectively as well as the left and right body shapes of male and female mullets from Cagayan de Oro River and Mandulog River respectively.

The sexual dimorphism observed between the Cagayan de Oro River and Mandulog River mullet populations can be accounted to biogeographical barriers which is a major driver of speciation (Wiley, 1988). Hossain et al., (2010), stated that variations by geographic separation are caused more likely by differences in water quality and other environmental conditions. Also, migration of Mugil cephalus is possible because it is widespread along the Philippines and tolerates both marine and freshwater conditions (Dusey et al., 2009).

\section{CONCLUSIONS AND RECOMMENDATIONS}

The variation in the body shape of males in Cagayan de Oro river using the first relative warp ranges from $41.70 \%$ to $41.92 \%$. In females the variation is $37.79 \%-44.59 \%$. Therefore, The phenotypic variation based on body shape of the flathead mullet is not significant within sexes in Cagayan de Oro river.

The variation in the body shape of males in Mandulog river ranges from $30.48 \%$ to $34.58 \%$. In females the variation ranges from $32.22 \%$ to $33.80 \%$. Therefore, there is no significant variation in the body shape within sexes of flathead mullets in Mandulog river.

Results from discriminant function analysis of both sexes of mullets from Cagayan de Oro River exhibited no significant variation which implies a distinct, uniform shape between sexes and therefore absence of sexual dimorphism in the Cagayan de Oro river. Mullets from Mandulog River showed significant variation, hence, sexual dimorphism of mullets can be seen in Mandulog River. Abundance of predators in Mandulog River can be the reason why there is significant phenotypic variability among mullets. Body shape variations in both sexes between the sites were also determined using the relative warp data from landmark-based geometric morphometric analysis. Left body shape of female mullet from Cagayan de Oro River varied significantly from the left body shape of male from Mandulog River which is applicable to both sexes. Biogeographical barrier is the main reason of the variation between body shapes which serves as physical barrier to gene flow.

Increased number of samples and increased sampling sites are recommended to obtain more reliable results. Use of high resolution cameras to obtain high quality and focused specimen is highly recommended also to be able to easily landmark the specimens. Multivariate Analysis of Variance (MANOVA) which includes confusion matrix and jackknifed confusion matrix table should be applied to reinforce the data from the discriminant function analysis (DFA).

\section{ACKNOWLEDGMENTS}

The researchers would like to acknowledge the financial support provided by DOSTASTHRD as well as the scholarship grants. Also, to the local officials and fishermen who helped during the collection of samples and to Michelle Barbon and Prof. Sharon Rose Tabugo for the technical assistance. 


\section{References}

[1] Adams, D. C., Rohlf, F. J., \& Slice, D. E. (2004). Geometric morphometrics: Ten years of progress following the "revolution'. Italian Journal of Zoology, 71, 5-16.

[2] Andersson, M. (1994). Sexual Selection. Princeton University Press, Princeton, New Jersey.

[3] Badyaev, A. V. \& Martin, T. E. (2000). Sexual dimorphism in relation to current selection in the house finch. Evolution 54: 987-997.

[4] Burns J. G., Di Nardo, P. and Rodd, F. H. (2009). The role of predation in variation in body shape in guppies Poecilia reticulata: a comparison of field and common garden phenotypes, Journal of Fish Biology, 75, 1144-1157.

[5] Casselman, S. J. and Schulte-Hostedde, A. I. (2004). Reproductive roles predict sexual dimorphism in internal and external morphology of lake whitefish, Coregonus clupeaformis. Ecology of Freshwater Fish, 13, 217-222.

[6] Darwin, C. (1871). The Descent of Man, and Selection in Relation to Sex. London: J. Murray.

[7] Hedrick, A. V. \& Temeles, E. J. (1989). The evolution of sexual dimorphism in animals: hypotheses and tests. Trends in Ecology and Evolution 4: 136-138.

[8] Hill, K. (2004). Smithsonian Marine Station at Fort Pierce. Retrieved from irl_webmaster@si.edu.

[9] Hossain, M., Nahiduzzaman, M., Saha, D., Khanam, H., Alam, M. (2010). Landmark-Based Morphometric and Meristic Variations of the Endangered Carp, Labeo calbasu, from Stocks of Two Isolated Rivers, the Jamuna and Halda, and a Hatchery. Zoological Studies 49(4): 556-563.

[10] Kitano, J., Mori, S. and Peichel, C.L., (2007). Sexual Dimorphism in the External Morphology of the Threespine Stickleback (Gasterosteus aculeatus). Copeia 2007: 336-349.

[11] Ritchie, M. G. (2007). Sexual selection and speciation. Annual Review of Ecology Evolution and Systematics. 38: 79-102.

[12] Rohlf, F. J., \& Marcus, L. (1993). A revolution in morphometrics. Trends in Ecology \& Evolution, 8, 129-132.

[13] Schulte-Hostedde, A. I., Millar, J. S. \& Gibbs, H. L. (2002). Female-biased sexual size dimorphism in the yellow-pine chipmunk: sex specific patterns of annual reproductive success and survival. Evolution 56: 2519-2529.

[14] Shine, R. (1989). Ecological causes for the evolution of sexual dimorphism: a review of the evidence. The Quarterly Review of Biology 64:419-461.

[15] Slatkin, M. (1984). Ecological causes of sexual dimorphism. Evolution 38:622-630.

[16] Spoljaric, M. A. and Reimchen, T. E. (2008). Habitat-dependent reduction of sexual dimorphism in geometric body shape of Haida Gwaii threespine stickleback, Biological Journal of the Linnean Society, 95, 505-516.

[17] Whitfield, A. K., Panfili, J., Durand, J. D. (2012). A global review of the cosmopolitan flathead mullet Mugil cephalus Linnaeus 1758 (Teleostei: Mugilidae), with emphasis on the biology, genetics, ecology and fisheries aspects of this apparent species complex. Rev. Fish Biol. Fish 22, 641-681.

[18] Zelditch, M., Swiderski, D., Sheets, H., \& Fink, W. (2004). Geometric morphometrics for biologists. London: Academic Press. 